\title{
A REVIEW OF DATA GOVERNANCE MATURITY LEVEL IN HIGHER EDUCATION
}

\author{
Hanung Nindito Prasetyo \\ Informatics Management Departement, School of Applied Science, Telkom University \\ Jl. Telekomunikasi Bandung Tekhnoplex Terusan Buah Batu Bandung West Java Indonesia 40257 \\ hanungnp@tass.telkomuniversity.ac.id
}

\begin{abstract}
Data governance in organization is unique. Every organization has a form of data governance in accordance with their respective needs. In some literature most of the industry, build data governance program based on the needs of data quality in achieving the company's goals. Some research have shown that data quality management is the foundation of data governance development in the industry. Although the data quality management is an important foundation, but in the development of the industry show the form of data governance that vary according to the needs and interests of the company. To see the effectiveness that data governance has been implemented well in an organization, it is needed a measurement mechanism of maturity level. However, to determine whether the measurements were carried out in accordance with the organization's goals, it will be require a clear base in determining the dimensions of the measurement. This research tried to describe the dimensions of which will be used during the activity measurement data governance maturity level within an organization. The measurement model used as a reference is the IBM data governance and DAMA International.
\end{abstract}

Keyword-Data Governance; Maturity Level; DAMA; $I B M$

\section{INTRODUCTION}

In general, the concept of data governance refers to the overall management of data availability, usability, integrity, quality, and security of data. Besides that data governance is a program to assign responsibility for the data, which is organizing the program for the organization staff together and continue to improve data quality through systematic mechanisms and enforcement of policies, roles, responsibilities, and procedures. Data governance program including in this case the organization or board, which has been defined including the division of authority, collection of procedures definition, and plans to carry out the procedure. The board also handles issues around ownership, share, access, use, and security of data as it is integrated and is adopted by the organization based on agreed business rules. Thus the explanation shows that data governance in the organization is unique. Each company has a form of data governance in accordance with their respective needs. In some literature most of the industry, build its data governance program based on the needs of data quality in achieving the company's goals. As statements (Begg and Caira, 2012)

Data governance formed from a convergence of several well-established areas concerned with data such as data quality management, data management systems, data security, and data administration.

They research the implementation of data governance in the industry in the medium and small level. While In the context of the enterprise, based on a survey by Rossom obtained graphically as Figure 1 . Figure 1 are based on 394 respondents in industry. The graph illustrates that the main requirement is the quality of data in large-scale industry. This shows that the management of data quality is the foundation data governance development in the industry. Although the data quality management is an important foundation, but in the development of the industry show the form of data governance that vary according to the needs and interests of the company (Russom, 2008):
Hanung Nindito Prasetyo

Jurnal Ilmiah Teknologi Informasi Terapan

Volume III, No.1, 15 Desember 2016 


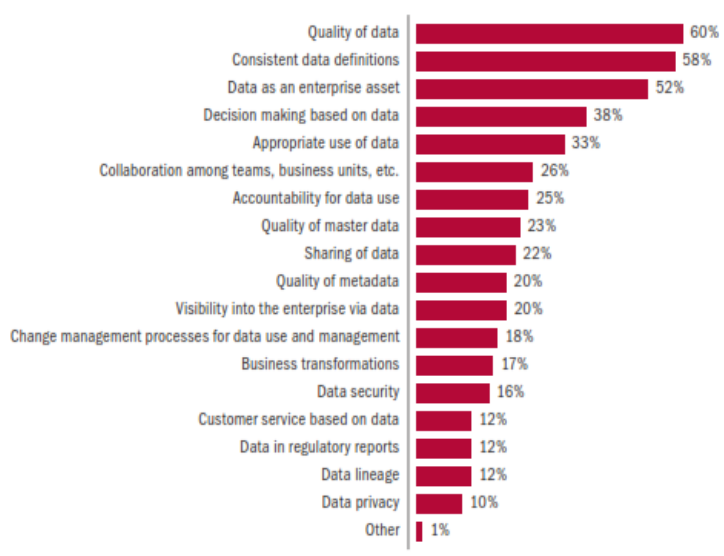

Figure 1. Survey Results Relating to Data Management (Russom, 2008)

In principle, any organization that uses information technology has doing data management. To see the effectiveness that data governance has been implemented well in an organization, it is needed a measurement mechanism of maturity level. However, to determine whether the measurements were carried out in accordance with the organization's goals, it will be require a clear base in determining the dimensions of the measurement. This research tried to describe the dimensions of which will be used during the activity measurement data governance maturity level within an organization. The measurement model used as a reference is the IBM data governance and DAMA International

\section{LITERATURE REVIEW}

\section{II.1 Information Technology Governance}

Originally the term IT Governance or information technology governance emerged in 1993 as a derivative of the main corporate governance and relationships with strategic objectives and IT management of an organization. information technology governance emphasizes the importance of the relationship between the IT organization and states that strategic IT decisions should be thought of Council rather than the CIO or other IT managers.

It is described by Weill and Ross (2004) that it is necessary to determine who is entitled to take decisions and make the accountability framework in order to produce the desired use of IT. ITGI adding basic mechanism as follows:
"... The leadership and organizational structures and processes that ensure that the IT organization to support and expand the organization's strategies and objectives." (IT Governance Institute, 2010)

On the basis that the governance of information technology (IT) aims to maximize the potential of existing resources, and avoid overlapping allocation of time, cost and human resources, as well as reducing the risk of the development of IT in order to ensure IT investments can provide optimal results. As in the previous explanation that IT governance is an integral part of corporate governance (GCG) which consists of the leadership (leadership), organizational structures, and processes that ensure that the IT organization to support and expand the organization's strategies and objectives. The main objective of IT governance is to:

a. Ensure that the investments in IT generate business value, and

b. Reduce the risk associated with IT.

Within a decade, information technology governance framework continues to evolve constantly. Prior to 2008, yet there is an IT governance framework is complete, but at that time there have been several frameworks available and can be used as a starting point in developing a model of IT governance.

\section{II.2 Data Governance}

Data governance is different from governance of information technology (IT). IT governance makes decisions about IT investments, IT application portfolio, and the portfolio of IT projects. Data governance strategies and aligning IT objectives with enterprise strategies and objectives. CobiT (Control Objectives for Information and Related Technology) provides IT governance standards, but only a fraction of the CobiT framework which deals with the management of the information on DS11. Data governance is specifically designed for the management of data assets. Data governance is at the heart of asset management data. This approach is in line with the concept of data governance Microsoft Corporation who explained that the data do not replace the IT governance, but as a complement [5]. IT governance focuses on defining the IT investment portfolio, performance settings, and evaluate and manage risks to the IT infrastructure. 
This ensures alignment of IT investments with the organization's mission and business objectives. Data governance, on the other hand, focuses on creating a context that enables organizations to align data management efforts with business goals, support regulatory compliance, and manage the risks associated with a particular data element in this case is the desire of the organization in protecting intellectual property, confidential trading, market data, including personal information. Figure 2 illustrates how the concept of IT governance, data governance, and compliance related to each other.

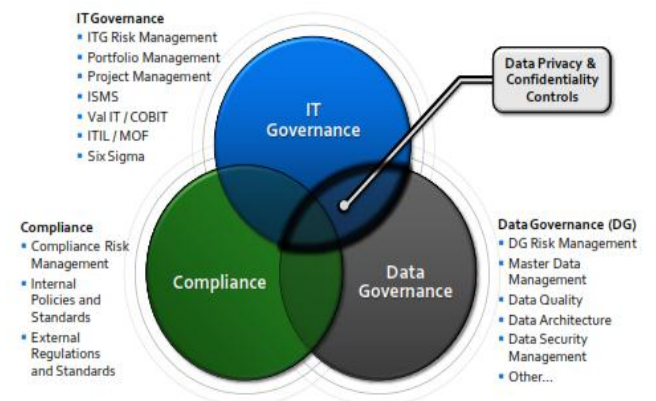

Figure 2. Concept of IT governance, data governance, and compliance related to each other in the approach Microsoft Corporation (Salido \& Voon, 2010).

There is some understanding of data governance and data governance. Here are some definitions of data governance:

a. Data governance is decision-making and authority for matters relating to the data. Data governance is a system of decision rights and accountability for process-related information, is carried out in accordance with the model and describe who can take what actions with what information, when, under what circumstances, using what methods (The Data Governance Institute, 2010).

b. Data governance is defined as the processes, policies, standards, organization, and technologies required to manage and ensure the availability, accessibility, quality, consistency, auditabilitas and data security within the enterprise or institution (Soares, 2011).

\section{II.3 Data Governance Framework}

Many ways are offered to solve the problems of data such as data governance framework by DAMA International. And the latest is a data governance unified process by vendors such as IBM Software providers (Soares, 2011).

\section{II.4 Data Governance DAMA International}

DAMA Association issued a reference framework and management of data standards known as DMBOK (Data Management Body of Knowledge) in 2009. DAMA International Association or now often referred to as DAMA International is a non-profit organization in the data management across the world founded in 1988 in Los Angeles. DAMA has more than 7500 members worldwide are composed of managers and data analysts. DAMA international grouping data governance function into 10 (ten) area as Figure 3.

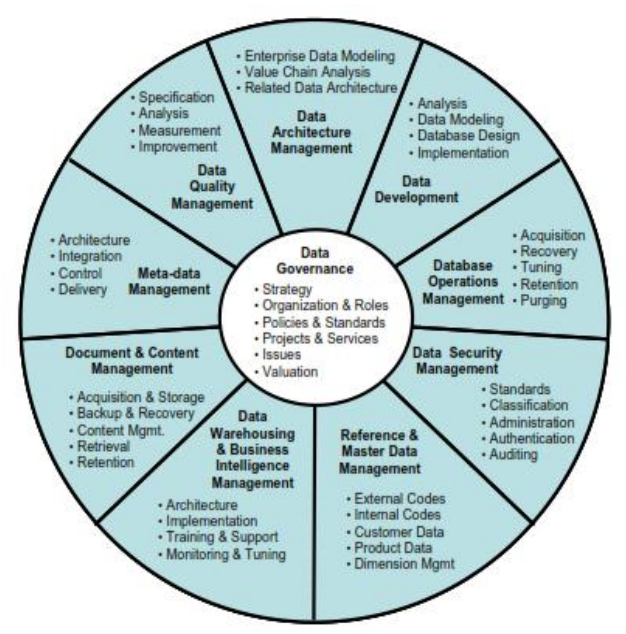

Figure 3. Data Governance Framework of DAMA Int. (Mosley, 2009)

In Figure 3, the model shows that the function of data governance is the important core. Data governance functions interact and affect other functions that surround it. Data governance regard to the authority and control (planning, monitoring, implementation) of the data assets. To supporting framework data governance function, DAMA set of 6 (six) focus areas of data management:

- Data Governance

- Data Development

- Database Operations Management

- Data Security Management

- Reference and Master Data Management

- Document and content management. 
The Focus-function downgraded to a data management function. As for the ten (10) in the data management function DAMA International (Mosley, 2009)

1. Data governance that includes planning, supervision and control over the management and use of data.

2. Management data architecture is an integrated part of the enterprise architecture.

3. Data Development which include analysis, design, development and testing, distribution and maintenance.

4. Database Operational management supports the physical structure defines the data asset recovery and performance needs for data and assist the service level in this area.

5. Data security Management, guarantee of privacy, trust and permissions.

6. The reference and Master Data Management. Managing major version and a replica of data, overseeing the manufacture, modification and deletion of code values and other reference data, define master data management needs, identification of master data management issues.

7. Data warehouse Management and business intelligence in providing open access to data for support the decision in terms of reporting and analysis.

8. Document and content management that includes storage, protection, and access rights index to find unstructured data.

9. Meta Data Management integrating, controlling and distributing metadata.

10. Data quality management define, supervise and improvise the data quality.

Then DAMA create the matrix as a column that should be done in data governance. The matrix is constructed as table 1 .

Table 1 shows that the DAMA is more focused on achieving technical data management.
Table 1. Data Governance DAMA Matrix Model (Mosley, 2009)

Elemen

\begin{tabular}{llllllll}
\hline Data Management & PG & A & D & RR & T & OT & OC \\
Functions & & & & & & \\
\hline Data Governance & & & & & & & \\
Data Architecture \\
Management
\end{tabular}

Reference \& Master Data

Management

Data Warehouse \&

Business intelligence

Management

Content \& Document

Management

Meta Data Management

Data Quality

Management

PG : Principle \& Goals; A : Activity; D : Distribution;

RR : Role \& Responsibility; $\mathrm{T}$ : Technology;

OT : Organizing Technical; OC : Organization \& Culture

\section{II.5 Data Governance Unified Process IBM}

International Business Machines (IBM) set up a data governance board as a leadership forum in 2004 for practitioners as the leader of data governance, leaders of information governance, leadership data services, the architect of an organization's data, the head of information security, the head of risk management, the head of compliance, and access rights and privacy leadership. The Council is focused discuss new issues related to the functioning of the organization that can effectively manage the data as an asset of the organization. Council focuses on the relationship between information, and business processes, optimize information for the organization. There are various problems in the governance of the data at the time of the beginning of the emergence of a governance board, such as (Adler, 2007):

- data governance inconsistencies can cause the loss of relationship between business goals and IT programs.

- data governance policies that are not related to the need-structured and reporting. 
- risks are not addressed from the perspective of the life cycle of data, policies, standards, and processing.

- metadata and business glossaries are not used to bridge the semantics related to differences in multiple applications within global organizations.

- governance across different data domains and organizational boundaries difficult to implement.

- data governance has elements of strategic and tactical, which is not always clear.

In fact, every organization will implement a data governance differently, mainly because of differences in business purposes. Some organizations focus on data quality, while others on the customer, and the other to ensure the privacy of data customer. Apart from this, every organization should in principle undertake certain steps to organize the data. IBM framework focus on the real problems associated with the data that is faced by the organization. Data Governance framework IBM can be gradual and continuous development cycle so clearly visible. In this case the data governance framework are built is not just a 'artifacts' but built gradually and strategically. Figure 4 illustrates the mapping of data governance IBM fourteen (14) step phase consisting of 10 (ten) steps required and four (4) additional optional steps (Soares, 2011).

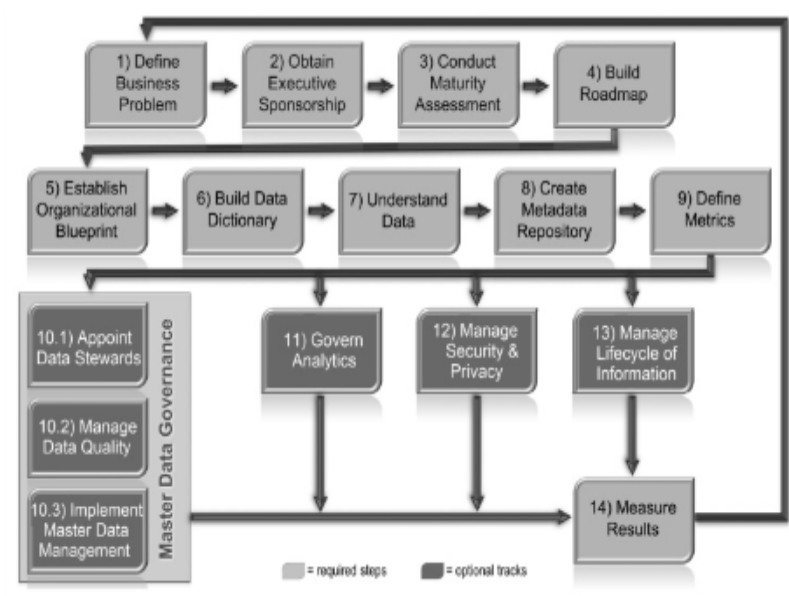

Figure 4. The Data Governance Framework IBM (Soares, 2011)

The focus of IBM data governance can be seen from the effective elements defined by IBM within 11 (eleven) category. 11 (eleven) are grouped into four categories, namely domain (Soares, 2011):

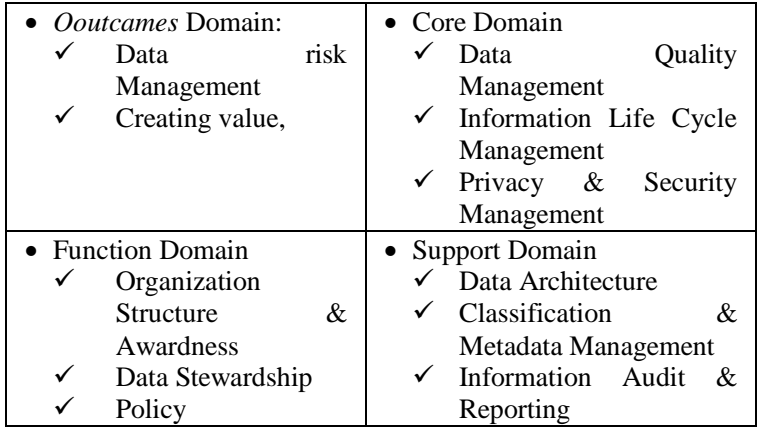

Figure 5. Domains Of Data Governance IBM

(Soares, 2011)

\section{II.6 Capability Maturity Model Integration (CMMI)}

CMMI is a process improvement approach that provides the essential elements of effective processes for the organization. Mechanisms using a questionnaire. Questionnaires maturity level here using the standard approach adopted from Capability Maturity Model (CMM) of the Software Engineering Institute (SEI). Presentation of CMMI can be divided into multilevel models (staged model) and continuous model. Differences in these models due to differences in the way to concentrate on process improvement. Selection of the model can be based on the approach to the region's ability or maturity of organizational processes. The viewpoint of regional capacity building process which concentrates the starting point and measure any improvement in each and regions one by one. As for the level of maturity in the governance of the data is as follows (SEI, 1986).

\section{Maturity level 0}

(Non-Existent) - a stage where Management processes do not exist

\section{Maturity level 1}

(Initial)- a stage where the process is going on normally ad hoc and unstable environments. The success that occurred more reflects individual competencies within the organization, rather than through the implementation of the agreed process or procedure. 


\section{Maturity level 2}

(Managed $)$ - the stage where the organization has a pattern for managing the associated process is based on the success of repeated experiences but do not have a standard pattern

\section{Maturity level 3}

(Defined)- The stage where the Organization is governed through a standardized process and used to establish consistency across the organization. Standards, process descriptions, and procedures on work customized organization, arranged according to a standard process in a particular project or organizational unit.

\section{Maturity level 4}

(Quantitatively managed) - The organization has set a target for quality and maintenance processes. Part of the selected process has significantly contributed to the overall performance and the process is controlled using statistical and other quantitative techniques.

\section{Maturity Level 5}

(Optimizing) - The entire process is capable of promoting the objective of the organization well and continuously, then constantly revised as a guide whenever there are changes in business objectives and used as criteria in managing process improvement.

\section{REVIEW OF MODEL \& MATURITY LEVEL DATA GOVERNANCE}

\section{III.1 Morphology of Data Governance}

In principle, morphological data governance consists of 2 (two) approaches, which approaches the structure and approach to the goals and objectives. This is as shown in Figure 5.

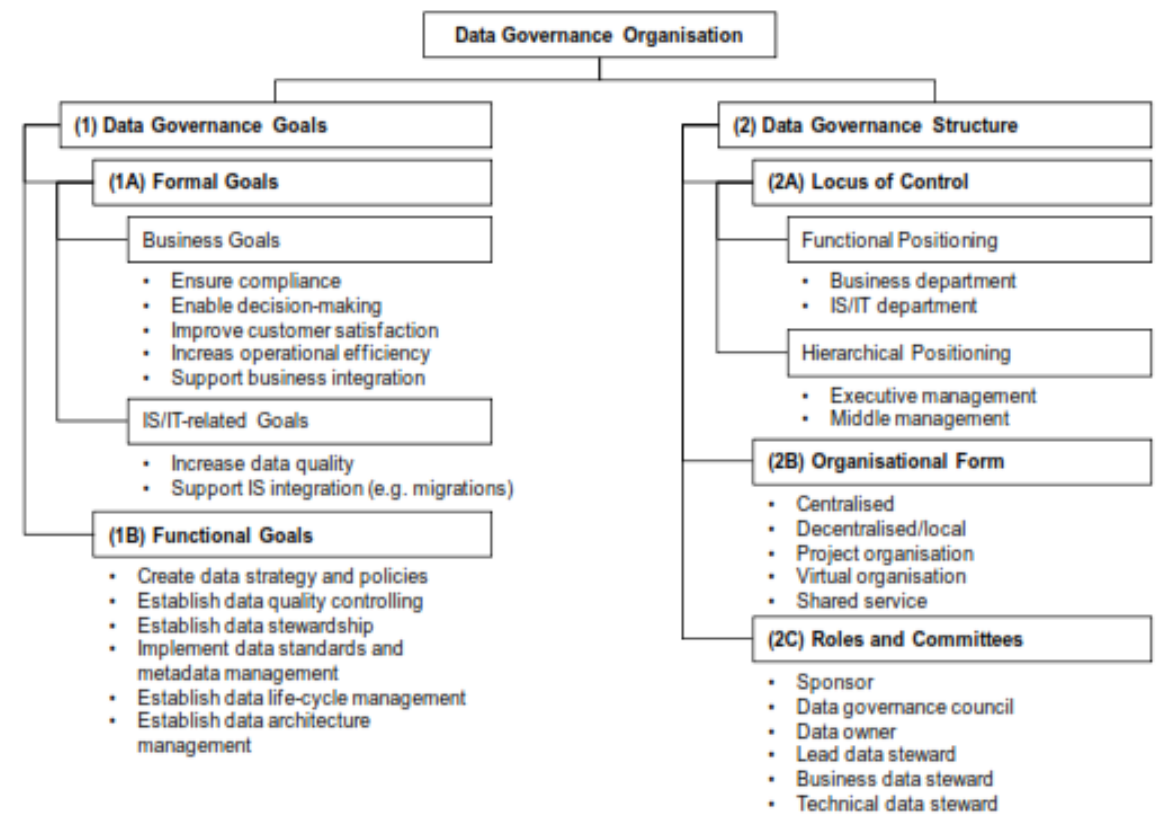

Figure 6. Morphology of Data Governance (Otto, 2011)

Figure 4 shows that to establish a data governance is based on two forms, namely:

- Based on the objectives / outcomes expected in data governance

- Based on the technical structure of Data Governance
Based on the shape, it appears that the data governance of DAMA International is based on fulfilling the function of data management structure. While IBM data governance more inclined to form data governance by objectives to be achieved. It can be shown in the phase formation of IBM data 
governance program begins with the identification of problems that occur in institutions, assess the level of maturity that is until eventually build roadmap of data governance based on the problems faced and the measurement results of existing data governance

To strengthen it would have taken two data governance framework that is most widely used as a reference, namely the IBM Data Governance and DAMA International. The following table 3 shows the relative position of the focus of both IBM Data Governance and DAMA International.

Table 2. Focus Of Relativity Positioning Data Governance IBM Dan DAMA International

\begin{tabular}{|c|c|c|}
\hline No & Focus IBM & Focus DAMA \\
\hline 1 & $\begin{array}{l}\text { Data Risk } \\
\text { Management }\end{array}$ & - \\
\hline 2 & Creating value & - \\
\hline 3 & $\begin{array}{l}\text { Struktur Organisasi } \\
\text { dan kepatuhan }\end{array}$ & - \\
\hline 4 & Data Stewardship & $\begin{array}{l}\text { Operational Database } \\
\text { Management }\end{array}$ \\
\hline 5 & Policy & Data Governance \\
\hline 6 & $\begin{array}{l}\text { Data Quality } \\
\text { Management }\end{array}$ & Data Quality Management \\
\hline 7 & $\begin{array}{l}\text { Information Life } \\
\text { Cycle Msnagement }\end{array}$ & $\begin{array}{l}\text { - Data Development } \\
\text { - Reference \& Master Data } \\
\text { Management } \\
\text { - Content \& Document } \\
\text { Management }\end{array}$ \\
\hline 8 & $\begin{array}{l}\text { Privacy \& Information } \\
\text { Security }\end{array}$ & Data Security Management \\
\hline 9 & Data Architecture & $\begin{array}{l}\text { Data Architecture } \\
\text { Management }\end{array}$ \\
\hline 10 & $\begin{array}{l}\text { Classification \& } \\
\text { Metadata }\end{array}$ & Metadata Management \\
\hline 11 & $\begin{array}{l}\text { Information Audit \& } \\
\text { Reporting }\end{array}$ & - \\
\hline 12 & - & $\begin{array}{l}\text { Data Warehouse \& Business } \\
\text { Inteligence Management }\end{array}$ \\
\hline
\end{tabular}

Source : (Prasetyo, 2013)

Table 3 shows that the focus of IBM data governance wider in scope than the DAMA International. But of these two models there are four (4) similarity of focus that is related policies, data quality, data security and data architecture. This shows that IBM has a scope broader Data Governance which includes risk management of data, creation and alignment of values, organizational structure and compliance, as well as policies while DAMA appears to be more focused in terms of data management or technical data management. IBM Data Governance in the focus seems oriented goals / achievements while DAMA International is the fulfillment of the technical structure of data governance. Therefore, based on the relative position and focus the process can be described that the process of integrated IBM data governance can become an 'umbrella' and fully supported by the 'artifacts' DAMA International. This can be illustrated in Figure 6.

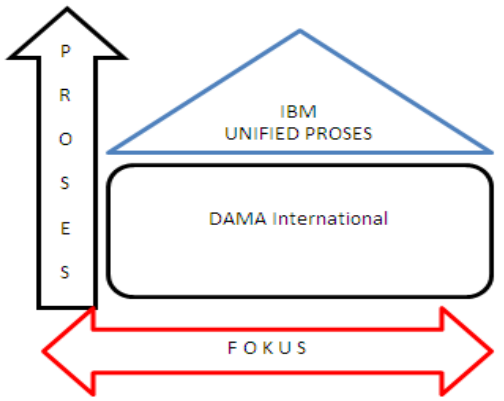

Figure 7. Relativity Positioning of IBM \& DAMA Data Governance (Prasetyo, 2013)

\section{III.2 Relationship between model \& maturity Level of Data Governance}

Model or framework that is used will determine the measuring instrument data governance maturity level. Organizations that want to build data governance with the fulfillment of the technical aspects of data management and technical data governance that can be used are elements of data governance DAMA. However, if you want to measure the targets to be achieved, the IBM approach that can be used. This research also recommends that if the data is not running on the management of the organization, can use DAMA International whereas if it has started can be measured with IBM models. Or even can combine between them according to the needs of the organization.

\section{III.3 The Test Measurement Data Governance Maturity level}

To gain an overview of the use of measurement data governance maturity level in this study, conducted case studies at the University of X. In this case study, measurement of data governance maturity level at the college to get the value of data governance maturity. The measurement approach uses two models namely the model DAMA International and IBM Unified Process Model. The study was conducted using survey techniques and 
conducted simultaneously at the university and then the results of a questionnaire prepared for later concluded. The survey respondents are subjects related to policy formulation, decision making, data management in the respective faculties and university level, such as the leadership ranks of university X, faculty leaders and their respective relevant field data management university as an academic unit and the unit manager of information systems. Table 4 shows the respondents of survey.

Table 3. Respondent Of Survei University X

\begin{tabular}{lc}
\hline \multicolumn{1}{c}{ Respondent } & Amount \\
\hline Leaders of University & 2 \\
Leaders of Faculty & 9 \\
Academic \& Information System Unit & 9 \\
\hline \multicolumn{2}{c}{ Total } \\
\hline
\end{tabular}

Source : researcher observation

\section{MEASUREMENT RESULT DATA GOVERNANCE MATURITY LEVEL}

\section{A. Survey Methods}

In this case study, the measurement data governance maturity level is done in colleges. The method used in this research is by using a questionnaire survey. The questionnaire used consisted of two types, the first questionnaire using the IBM approach and a second questionnaire approach DAMA International. The survey was conducted among respondents same but in a different time and carried out simultaneously at the institution. then the results of the questionnaire prepared for later concluded.

\section{Figure 8. Quesioner Model}

\begin{tabular}{|l|l|l|l|l|l|l|l|}
\hline No & Element & \multicolumn{6}{|c|}{$\begin{array}{l}\text { Maturity Level of } \\
\text { Data Governance }\end{array}$} \\
\hline & & $\mathbf{0}$ & $\mathbf{1}$ & $\mathbf{2}$ & $\mathbf{3}$ & $\mathbf{4}$ & $\mathbf{5}$ \\
\hline 1 & Element 1 & & & & & & \\
\hline & a. & & & & & & \\
\hline & b. & & & & & & \\
\hline 2 & Element 2 & & & & & & \\
\hline & a. & b. & \multicolumn{7}{|c|}{} \\
\hline & Etc. & & & & \\
\hline 3 & &
\end{tabular}

Respondents were asked to provide ceklish mark $(\sqrt{ })$ on the questionnaire that has been provided. After all respondents have filled the accumulated tally conducted using both the average value on each element and overall value.

The formula for calculating the average value of each element is as follows:

Maturity Indeks of element $=\frac{\text { Total Answer of elements }}{\text { Total Question of elements }}$

As for the formula for the overall average value is as follows:

$$
\text { Total Maturity Indeks }=\frac{\text { Total Answers }}{\text { Total Questions }}
$$

The two questionnaires, using the same calculation formula. The elements in the questionnaire based on the maturity level IBM:

1. Term Of Risk Management

2. Creating value

3. Policy

4. Organization Structure and Awardness

5. Data Stewardship

6. Data Quality Management

7. Information Life Cycle Management

8. Privacy and Security

9. Data Architekture

10. Clasification and metadata

11. Information Audit and reporting

While the level of maturity with DAMA approach is based on element:

1. Data Governance

2. Data Architecture Management

3. Data Development

4. Operational Database Management

5. Dataq Security Management

6. Reference \& Master Data Management

7. Data warehouse \& Business Inteligence Management

8. Content \& Document Management

9. Metadata Management

10. Data Quality Management

\section{B. Survey Result IBM Model}

The following analysis of the results of recapitulation calculation described questionnaire 
data governance maturity level and gap analysis at the University X.

Table 4. Recapitulation Maturity Level Data Governace In University X With Ibm

\begin{tabular}{llc}
\hline \hline No & Dimention & $\begin{array}{c}\text { Maturity } \\
\text { Level }\end{array}$ \\
\hline \hline 1 & Term Of Risk Management & 2,00 \\
2 & Creating value & 2,33 \\
3 & Policy & 1,89 \\
4 & Organization Structure and Awardness & 2,68 \\
5 & Data Stewardship & 2,40 \\
6 & Data Quality Management & 1,87 \\
7 & Information Life Cycle Management & 2,07 \\
8 & Privacy and Security & 2,11 \\
9 & Data Architekture & 2,30 \\
10 & Clasification and metadata & 1,81 \\
11 & Information Audit and reporting & 2,42 \\
\hline \hline Average & $\mathbf{2 , 1 4}$ \\
\hline \hline
\end{tabular}

Source: (Prasetyo, 2013)

As the description above table, terms of risk management, creation, and alignment of values, organizational structure and awardness, Data stewardship, security and privacy, data architecture auditing and reporting information of university $\mathrm{X}$ at the level 2 - where the level Managed.

\section{Survey Result With DAMA International Model}

Based survey data governance maturity levels in college obtained the results of the calculation as Table 6.

Table 5. Recapitulation Maturity Level Data Governance In University $X$ With Dama

\begin{tabular}{clc}
\hline No & Dimention & $\begin{array}{c}\text { Maturity } \\
\text { Level }\end{array}$ \\
\hline 1 & Data Governance & 2,13 \\
2 & Data Architecture Management & 3,00 \\
3 & Data Development & 2,22 \\
4 & Operational Database Management & 2,31 \\
5 & Dataq Security Management \& Master Data & 2,11 \\
6 & Reference \& & 2,41 \\
& Management & 1,65 \\
7 & Data warehouse \& Business & \\
& Inteligence Management & 2,52 \\
8 & Content \& Document Management & 1,53 \\
9 & Metadata Management & 2,18 \\
10 & Data Quality Management & 2,21 \\
\hline Average
\end{tabular}

Source : (Tridalestari, 2014)

Both of table shows that data governance maturity level at university have an average rating of 2.14 based on IBM and the average value of 2.21 based DAMA or can be inferred by the results obtained by the two approaches are at level 2 (which means that the level of maturity of governance at stage of managed), where the organization has a pattern for managing the associated process is based on the successful experience recurrent but not a standard pattern. Quite apart from these results, it can be shown that in Table 5, the dimensions of data governance at DAMA has a value of 2.13 or close relevance to the average value of data governance maturity level IBM by 2.14. This means that the dimensions of the DAMA data governance can represent measurement data governance maturity level but it is not known variable aspects of derivatives or less detail. In addition, the IBM approach shows more of 'governance' in comparison with the approach of DAMA International.

Furthermore, it can be shown that morphologically both, goals and structure, data governance in Telkom University is still in the category of managed.

\section{CONCLUSION}

This research concluded that if organizations want to measure the maturity level of data governance is based on the fulfillment of the governance structure of the data can use DAMA International approach for a more technical nature. However, if organization want to measure the targets to be achieved, the IBM data governance approach that can be used. Research is once again recommends that if the data is not running on the management of the organization, can use DAMA International whereas if it has started can be measured with IBM models.

\section{REFERENCES}

Carolyn E. Begg dan Tom Caira. (2012). Exploring the SME quandary: Data Governance in practice in small to medium-sized enterprise sector. The Electronic journal Information System Evaluation, ejise.com.

Russom, Philip. (2008). "Customer Data Integration". Business Inteligence Journal.

Weill, P., \& Ross, J. W. (2004). IT governance: How top performers manage IT decision rights for superior results. Harvard Business Press.

Salido J., Voon P. (2010). A Guide to Data Governance Privacy, Confidentiality and Compliance. Microsoft Corporation.

Adler, Steve.(2007). The IBM Data Governance 
Maturity Model: Building a Roadmap for Effective Data Governance. Whitepaper of IBM Corporation.

Soares, Sunil. (2011). The IBM Data Governance Unified Process; Driving Business Value with IBM Software and Best Practices. USA Ketchum : MC PRESS.

Mosley M., Brackett M., Earley S., Henderson D.,(2009). The DAMA Guide to The Data Management Body of Knowledge (DAMADMBOK Guide). USA : Technics Publications, LLC.

Software Engineering Institute (SEI), (1986). Capability Maturity Methode. USA Defence Departement. Carnegie Mellon University: Pittsburgh.

Prasetyo, Hanung N., (2015). Pengukuran Maturity Level tata kelola data di Universitas X dengan menggunakan Standar IBM, Proseeding SESINDO 2015 ITS Surabaya.

Otto, Boris. (2011). A morphology of the organisation of data governance. In ECIS, vol. 20 , no. 1 , p. 1 .

Prasetyo, Hanung Nindito. (2013). Designing of Data Governance Model In Higher Education, Case study: Telkom University". Bandung Institute of Technology, Not Published.

Tridalestari, Ferra Arik. (2014). Identification of Data Governance funtion with DAMA International framework in higher eduation. Bandung Institute of Technology. Not published. 